\title{
Temporal variations in phenological events of forests, grasslands and desert steppe ecosystems in Mongo- lia: a remote sensing approach
}

\author{
N. Dugarsuren, C. Lin
}

Dugarsuren N., Lin C., 2016. Temporal variations in phenological events of forests, grasslands and desert steppe ecosystems in Mongolia: a remote sensing approach. Ann. For. Res. 59(2): 175-190.

Abstract. The occurrences of phenological events are important variables in the evaluation of the influence of climate change on terrestrial ecosystems. Changes in climate can cause significant changes in the timing and duration of phenological events. Information related to large-scale phenology is therefore useful for exploring the seasonal and inter-annual variability in vegetation-climate interactions. This study aimed to obtain the timing and temporal pattern of the onset of green-up and dormancy (OG and OD) and length of growing season (LGS) using the normalized difference vegetation index (NDVI) and enhanced vegetation index (EVI) for Forest, Grassland, and Desert steppe in Mongolia over the 10-year period from 2000 to 2009. Results demonstrated that phenological events can be differentiated by multi-temporal NDVI and EVI data and that the timing ascribed to OG and OD is slightly different between the two indices. In general, NDVI and EVI agreed that the OG of forest varied from late May to middle July. The OG of grassland and desert steppe suggested by NDVI were from late May to middle July and from middle May to middle July respectively, however EVI suggested an earlier timing of OG. NDVI and EVI also showed similar variation for the timing of OD from early September to early October. The derived LGS showed the least variation for forest, highest variation for desert steppe, and only moderate variation for grassland. Grassland and desert steppe experienced high positive and negative variations in the OG and LGS during the years from 2000 to 2009 . These regions might be vulnerable to global change and are likely to be strongly affected by meteorological changes.

Keywords phenological events; onset of green-up; onset of dormancy; length of growing season; peak time of vegetation maturity; vegetation indices; MODIS NDVI and EVI

Authors. Narangarav Dugarsuren, Chinsu Lin (chinsu@mail.ncyu.edu.tw) Department of Forestry and Natural Resources, National Chiayi University. 300 University Road, Chiayi (60004), Taiwan.

Manuscript received June 3, 2015; revised June 10, 2016; accepted June 20, 2016; online first July 28, 2016. 


\section{Introduction}

Phenology refers to the study of the timing of seasonal biological activities of periodic plant life cycles (Haggerty \& Mazer 2008). Vegetation typically shows seasonal and annual dynamics during it's life cycle that can be identified as phenological events including vegetation green-up, bud flashing, budburst, leaf out, leaf coloring, leaf fall and leaf senescence (Chesnoiu et al. 2009). Changes in climate can result in large changes in the timing and duration of these phenological events (Menzel et al. 2006, Parmesan 2006, Soleimani et al. 2014). For example, the annual air temperature in Mongolia over the period from 1940 to 2007 has increased by $1.6^{\circ} \mathrm{C}$, and the change in seasonal temperatures was $1.8,1.1$, and $1.0^{\circ} \mathrm{C}$ for spring, summer, and autumn respectively (Gomboluudev 2008). In contrast, the annual precipitation has decreased by $7 \%$ as an average over the whole country (Batima \& Dagvadorj 2000, Gomboluudev 2008). Therefore the timing of plant phenological events and their lengths are important for assessing the effects of seasonal and inter-annual climate change on vegetation in Mongolia.

A number of previous phenological studies utilize field measurements to observe inter-annual variations of phenological events and responses to climate change at the species level (Serbin et al. 2009, Sacks \& Kucharik 2011, Shen et al. 2011, van Oort et al. 2011). A field measurement approach makes it hard to acquire information on regional scale responses to changing climate as it is impractical to conduct meaningful field measurements covering large regions. Remote sensing has the capacity to identify the reaction of vegetation to the coordinated impacts of ecological variables and gives an opportunity to gauge their spatial and temporal variations at regional or even global scales. Radiometric and geometric properties of the MODerate resolution Imaging Spectroradiometer (MODIS), in combination with improved spatial and temporal resolution, en- able the monitoring of photosynthesis activity at larger spatial and longer temporal scales (Running et al. 1994, Justice et al. 1998). Normalized Difference Vegetation Index (NDVI) (Tucker 1979) has been extensively used to interpret seasonal cycles in the phenological events of vegetation because seasonal changes of NDVI correspond well with vegetation seasonal events (Chen et al. 2001, Zhou et al. 2001). However, NDVI is sensitive to atmospheric conditions and the soil background whilst less sensitive to changes in high biomass areas. To overcome these restrictions, Enhanced Vegetation Index (EVI) (Huete et al. 1997) was proposed to optimize NDVI by incorporating reflectance values in the Blue, Red and NIR regions of the electromagnetic spectrum.

More recently various methods have been applied to extract information regarding phenological events using VIs. These include NDVI thresholding (Parmesan 2006), the greatest NDVI increase (Kaduk \& Heiman 1996, Lee et al. 2002, Piao et al. 2006), moving averages (Reed et al. 1994), and empirical equations (Moulin et al. 1997). Zhang et al. (2003) suggested that a suitable method should be flexible for global-scale applications and able to account for the characteristics of the multiple growth cycles in ecosystems. That is, if a threshold method is applied to determine the Onset of Green-up (OG) and the Onset of Dormancy (OD), the threshold values have to be adjustable in order to account for various vegetative circumstances. Fortunately, a series of long-term values of vegetation indices can be applied to satisfy the need of such threshold method. According to the modified threshold method (Piao et al. 2006), the OG and OD is diagnosed at the inflection point (a specific date) of the curve of serial vegetation index when it begins to ascend or descend in a year duration. This method was furthermore found to be more sensitive to climate change (Jeong et al. 2011, Shen et al. 2011), highly correlated with a ground observed phenology index 
(Studer et al. 2007) and presumably reduced climatic impacts such as aerosols, clouds, disturbances, and defoliation on annual values (Jeong et al. 2011).

This study focused on the following four transition dates of vegetation phenology: (1) OG, the date when plant photosynthetic activity begins, (2) maturity or peak time, the date when plant reach to maximum, (3) OD, the date when plant photosynthetic activity becomes near zero, (4) Length of Growing Season (LGS), i.e., the period between $\mathrm{OG}$ and OD, due to the possibility to infer these from remote sensing imagery (Zhang et al. 2003). The objectives of this study were to (i) determine the timing of these phenological events using the modified threshold method, (ii) determine temporal patterns of these phenological events and (iii) examine the differences in these phenology events when derived using two VIs for three vegetation types, Forest, Grassland (GL), and Desert steppe (DS), of Mongolia over the 10 year period from 2000-2009.

\section{Material and methods}

\section{Study area}

Mongolia is one of the largest landlocked countries in the world, covering 1,564 square kilometres in area and extending between the latitudes of $41^{\circ} 35^{\prime}-52^{\circ} 09^{\prime} \mathrm{N}$ and longitudes of $87^{\circ} 41^{\prime}$ - 11956’E (Figure 1). The average altitude is $1580 \mathrm{~m}$ above sea level (Tsegmid 1969). The climatic characteristics of Mongolia are mainly sunny days, long and cold winters, and dry, cold and windy conditions in the spring (Batjargal 1996). Generally, the terri- tory of Mongolia consists of six natural zones (alpine, taiga, forest steppe, steppe, desert steppe, and desert) with remarkable differences in terrain and climatic characteristics. Three main vegetation types (forest, grassland and desert steppe) were chosen for this analysis. Annual maximum temperature in the forest region ranges from $12-16{ }^{\circ} \mathrm{C}$, in grassland from $15-19{ }^{\circ} \mathrm{C}$ and in desert steppe from $22-26^{\circ} \mathrm{C}$. The annual maximum precipitation ranges from $59-62 \mathrm{~mm}$ in the forest region, $44-48 \mathrm{~mm}$ in grassland and $20-24 \mathrm{~mm}$ in the desert steppe. Growing season or summer continues 90-112 days in the forest, 112-125 days in grassland, and 125-130 days in desert steppe (Jigmed 2006).

\section{Data preparation}

MODIS Terra Surface reflectance (MOD09A1) data provided by the U.S. Geological Survey (USGS) Land Processes Distributed Active Archive Center (LP DAAC) was used as a basis in this study. It provides an 8-day gridded level-3 image of the MODIS 1-7 bands (blue: $459-479$ nm, green: $545-565 \mathrm{~nm}$, red: $620-670$ nm, NIR: $841-875 \mathrm{~nm}$, NIR II: $1230-1250 \mathrm{~nm}$, SWIR: 1628-1652 nm, and SWIR II: 2105$2155 \mathrm{~nm}$ ) at $500 \mathrm{~m}$ spatial resolution. The retrieved data were in the Sinusoidal projection.

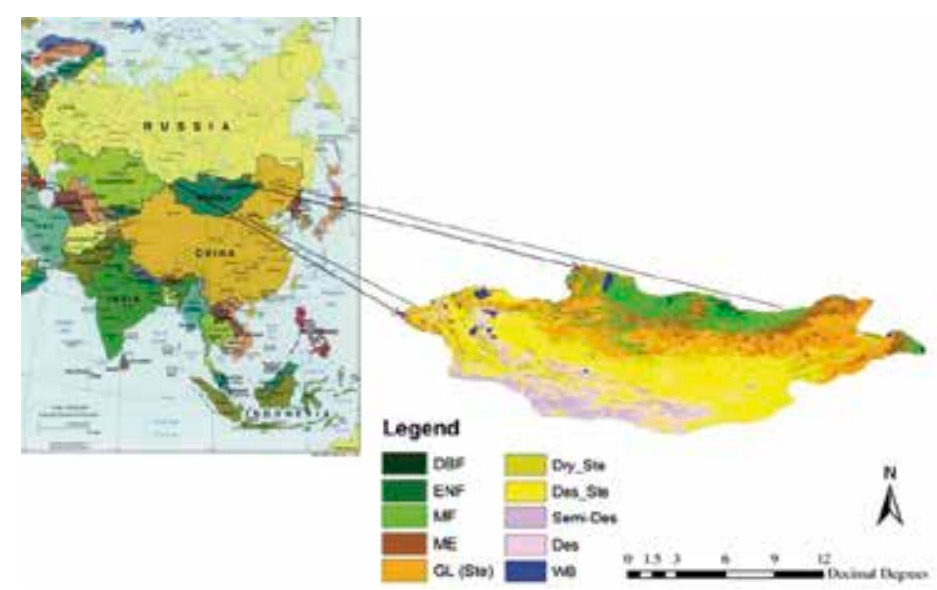

Figure 1 The Geographic location (left) and the land cover map (right) of the study area 
All bands of the data were imported (from .hdf /Hierarchical Data Format/ into .img format), mosaicked (6 tiles: covering entire of area of Mongolia, H23V03/04, H24V03/04, $\mathrm{H} 25 \mathrm{~V} 03 / 04$, and H26V04 into a single tile) and reprojected (sinusoidal to Geographic Latitude and Longitude projection with WGS84 datum and nearest neighbor resampling method) using MODIS Reprojection Tool (MRT). Then, a clipping process using the boundary of Mongolia was carried out to obtain the whole area of Mongolia for this study. Finally, Vegetation Indices EVI and NDVI were derived from Blue, Red, and NIR bands using Eqs. (1) and (2) respectively, where the $\mathrm{R}_{\text {nir }}$ is the reflectance of NIR (MODIS band 2), the $\mathrm{R}_{\text {red }}$ is the reflectance of red (MODIS band 1), and the $\mathrm{R}_{\text {blue }}$ is the reflectance of blue (MODIS band 3 ) of the solar spectrum. Based on a suggestion by Tucker [22], the coefficients in Eq. (2) for $\mathrm{G}$ : gain factor, L: background adjustment factor, $\mathrm{C}_{1}$ and $\mathrm{C}_{2}$ : the aerosol resistance coefficients are $2.5,1,6$, and 7.5 respectively. After that, all the individual 8-day images from 2000 to 2009 were then stacked into a single image with 260 bands (26 images for one year multiplied by 10 years equals to 260 ).

$$
\begin{aligned}
& N D V I=\left(R_{\text {nir }}-R_{\text {red }}\right) /\left(R_{\text {nir }}+R_{\text {red }}\right) \\
& E V I=G\left(\frac{R_{\text {nir }}-R_{\text {red }}}{R_{\text {nir }}+C_{1} R_{\text {red }}-C_{2} R_{\text {blue }}+L}\right)
\end{aligned}
$$

A land cover map (Fig 1) produced by Dugarsuren et al. (2011) using MODIS Vegetation Index product (MOD13Q1) based on the International Geosphere Biosphere Program (IGBP) classification scheme (Gao \& Yu, 1998) was utilized to derive a map of vegetation types. Briefly, the forest was composed of Deciduous Broadleaf Forest (DBF), Evergreen Needle leaf Forest (ENF), and Mixed Forest (MF); the grassland was a collection of meadow, grassland, and dry steppe; the desert steppe included desert steppe and semi-desert grassland). In corresponding to the VIs images, 178 a number of 700 pixels was randomly sampled from each of the vegetation types for statistical analysis. Additionally, the average of the 700 sample of each vegetation type represented a generalized noise-free VIs of each vegetation type during the period.

\section{Phenological events extraction and statistical analysis}

The modified threshold method developed by Piao et al. (2006) was applied for detecting the OG and OD of the forest, grassland, and desert steppe from 2000 to 2009 using MODIS NDVI and EVI data. The method of diagnosing the OG and OD was a 5-step procedure. First, a set of pixels distributed over the study area were selected by stratified random sampling from the VIs images in order to generate inter-annual dynamics of vegetation types. Those regions of interest (ROI) were selected from the land cover map in accordance with vegetation types; forest, grassland and desert steppe. Second, 10-year averaged seasonal VIs dynamics at 8-day intervals for each vegetation type were calculated based on these pixels in ROIs to determine maximum and minimum rate of changes during the 10 years. The rate of changes $\left(V I_{\text {ratio }}\right)$ was calculated using eq. (3), where $t$ is 8-day interval of time.

$V I_{\text {ratio }}(t)=\left[V I_{(t+1)}-V I_{(t)}\right] / V I_{(t)}$

Third, based on the maximum and minimum values of $\mathrm{VI}_{\text {ratio, }}$ we determined the threshold value to be used to define OG and OD of each year and the average date to determine $\mathrm{OG}$ and OD. The corresponding time $(\mathrm{t})$ to the maximum $\mathrm{VI}_{\text {ratio }}$ was determined as the average date of $\mathrm{OG}$ and corresponding $\mathrm{VI}_{(\mathrm{t})}$ was used as the VIs threshold for the OG of each vegetation types. Similarly, the corresponding time (t) to the minimum $\mathrm{VI}_{\text {ratio }}$ was defined as an average date of OD and corresponding $\mathrm{VI}_{(\mathrm{t}+1)}$ at the time $(\mathrm{t}+1)$ as the threshold of VIs for the OD. Fourth, a smoothing process was performed on the VI values in every year before 
extraction the date of OG and OD in each year. To represent $\mathrm{VI}_{\text {ratio }}(\mathrm{t})$ as a function of the day of the year, smoothing was performed with sixth-degree polynomial function (Piao et al. 2006) on the time-series VIs curve from April to October (the growing season of vegetation in Mongolia), the corresponding Julian day for the vegetation types for each year. Finally, the OG and OD were defined for each year as the day when a smoothed curve passes the NDVI or EVI threshold. Furthermore, the period within date of OG and OD were used to derive the LGS for each vegetation types from 2000 to 2009 .

A two-way ANOVA test was applied to examine if the NDVI and EVI-derived phenology events are statistically equivalent to each other. This test was also applied to investigate if the forest, grassland, and desert steppe have similar vegetation events. Relative quantity modelling was performed to explore the agreement between NDVI and EVI derived LGS patterns in the same year. To do this the pattern of LGS of each vegetation types based on the inter-annual dynamic of phenological events was first found and then the years grouped by the same pattern. Validation of the phenological events from ground measurement was complicated because of the differences of spatial resolution (White et al. 2005), since ground measurements of phenological events are mainly dedicated to a few species while the remotely sensed dataset averages species over the spa- tial extent of one pixel. Following White et al. (2005) the results of this study were directly compared with the results of previous studies for validation purposes.

\section{Results}

\section{Intra-annual variations in Vls}

Prior to the analysis, efforts were made to observe differences in annual variations of VIs with relevance to climatic variations. Generally, intra-annual deviation of both NDVI and EVI in vegetation types showed no dramatic differences. The deviations from their long term mean for both NDVI and EVI are in the same directions in any given year with the exception of 2007 and 2009 for forest; 2001, 2006 and 2008 for GL; 2002 for DS (Fig. 2). There were no significant difference between NDVI and EVI deviations at $\mathrm{P}>0.05$ through the analysis of one-way t-test.

The annual mean precipitation from 2000 to 2009 deviated from its long-term mean value at a figure of $\pm 12 \mathrm{~mm}$ (bar chart in Fig. 3) and the annual mean temperature changed in a deviation of $\pm 1.5^{\circ} \mathrm{C}$ from the 10 years longterm temperature mean (line chart in Fig 3). In general, the Pearson's correlation test showed that NDVI and EVI revealed somewhat of a positive relationship with the annual average of precipitation and temperature. While the

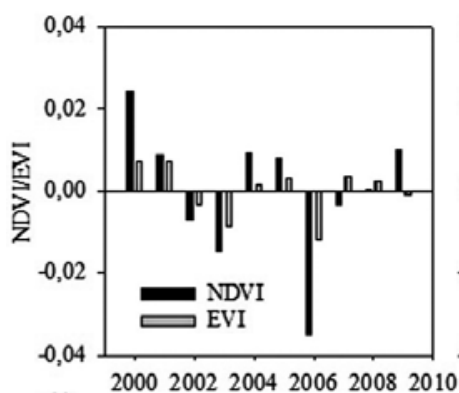

(a)
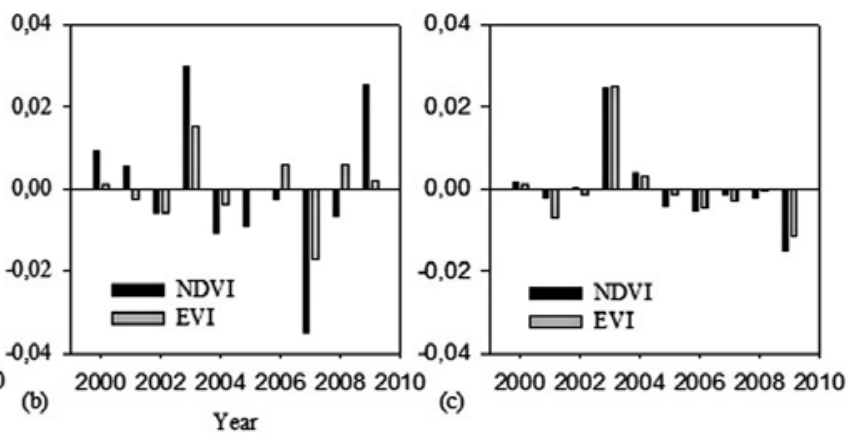

Figure 2 Intra-annual deviations of NDVI and EVI from long term (10-year) means: Forest (a), GL (b) and DS (c) 


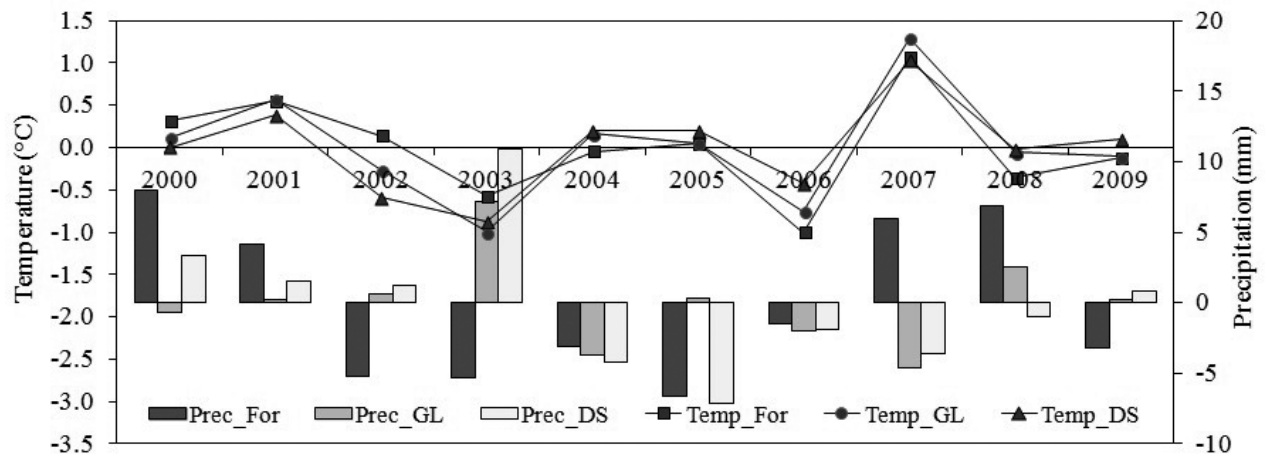

Figure 3 Annual deviation of temperature (line chart) and precipitation (bar chart) of each vegetation types

significance was not simultaneously observed in each of the vegetation types and also the vegetation indices at the 0.05 probability level (Table 1).

Specifically, the NDVI over the Forest area was not related to the deviation level of the temperature and precipitation, however the EVI was significantly related to the temperature $(r=0.760, p<0.011)$. In the area of GL, the relationship between both vegetation indices and both meteorological factors were significant. The correlation coefficient of NDVI vs precipitation and temperature is 0.715 $(\mathrm{P}<0.020)$ and $0.648(\mathrm{P}<0.043)$ respectively and that of EVI vs precipitation and temperature is $0.788(\mathrm{P}<0.007)$ and $0.866(\mathrm{P}<0.001)$ respectively. Additionally, the NDVI and EVI over the DS area had correlation coefficients with the precipitation of $\mathrm{r}=0.639(\mathrm{P}<0.049)$ and $\mathrm{r}=0.617(\mathrm{P}<0.058)$.

According to the descriptive statistics, June for Forest, July for GL and DS have the highest variability as shown in Figs. $4 a$ and $4 b$; followed by October, June (Fig. 4a) or Aug (Fig. 4b), and Aug for forest, GL and DS, respectively. Both NDVI and EVI values gradually increased until reaching their maximum and then decreased as Julian day increases, forest and grassland areas have especially rapid changes throughout a year.

Table 2 lists the threshold values of both NDVI and EVI index values that were used

Table 1 Pearson's correlation coefficients between the deviations of VIs (NDVI and EVI) and the deviations of an average value of 10 -yrs period climatic variables (temperature and precipitation)

\begin{tabular}{llllll}
\hline \multirow{2}{*}{ VIs } & \multirow{2}{*}{ Vegetation types } & \multicolumn{3}{c}{ Precipitation } & \multicolumn{3}{l}{ Temperature } \\
\cline { 3 - 6 } & For & $r$ & Sig. & $r$ & Sig. \\
\hline \multirow{2}{*}{ NDVI } & GL & 0.303 & 0.395 & 0.590 & 0.072 \\
\cline { 2 - 6 } & DS & $0.715^{*}$ & 0.020 & $0.648^{*}$ & 0.043 \\
\hline \multirow{2}{*}{ EVI } & For & $0.639^{*}$ & 0.049 & 0.489 & 0.151 \\
\cline { 2 - 6 } & GL & 0.544 & 0.104 & $0.760^{*}$ & 0.011 \\
\cline { 2 - 6 } & DS & $0.788^{* *}$ & 0.007 & $0.866^{* *}$ & 0.001 \\
\hline
\end{tabular}

Note. Abbreviation: ${ }^{*}$ and $* *$ indicate that a coefficient is significant at the 0.05 and 0.01 level respectively (2-tailed). 

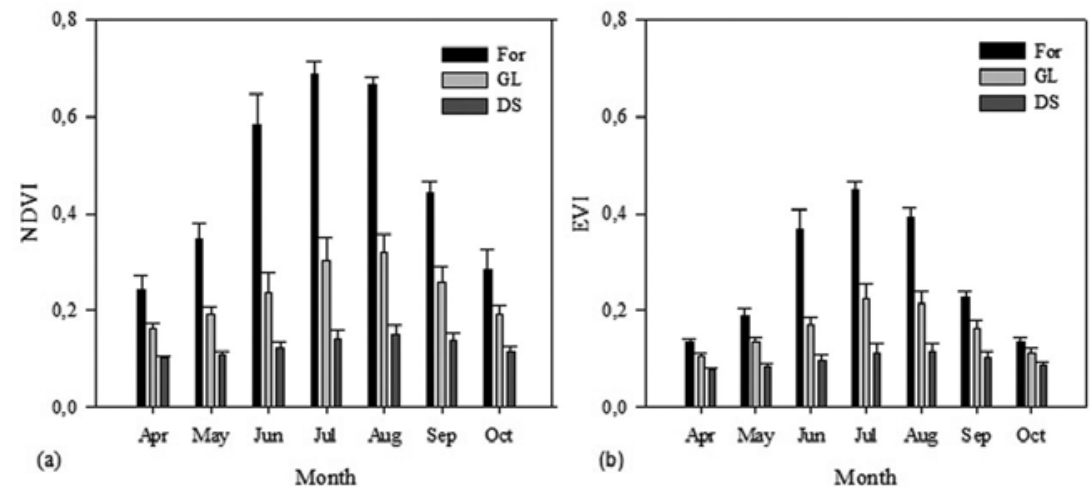

Figure 4 The descriptive statistics of monthly NDVI (a) and EVI (b) for the three vegetation types. Bar chart shows the monthly mean values of each Vis which calculated from 10 years observation values of each month. Error bar shows the standard deviation of monthly NDVI and EVI

Table 2 Threshold values of NDVI and EVI used for the determination of OG and OD

\begin{tabular}{llllllll}
\hline \multirow{2}{*}{ VIs } & $\begin{array}{l}\text { Vegetation } \\
\text { types }\end{array}$ & OG & \multicolumn{3}{c}{ OD } & Peak \\
\cline { 2 - 8 } & Average date & Threshold & Average Date & Threshold & Average date & Value \\
\hline \multirow{2}{*}{ NDVI } & Forest & Mid May & 0.361 & Late Sep. & 0.469 & Late July & 0.69 \\
\cline { 2 - 7 } & Grassland & Mid June & 0.234 & Late Sep. & 0.225 & Late July & 0.32 \\
\cline { 2 - 8 } & DS & Mid June & 0.122 & Late Sep. & 0.135 & Late Aug & 0.15 \\
\hline \multirow{2}{*}{ EVI } & Forest & Mid May & 0.193 & Late Sep. & 0.155 & Early July & 0.45 \\
\cline { 2 - 8 } & Grassland & Mid May & 0.126 & Late Sep. & 0.140 & Late July & 0.23 \\
\cline { 2 - 8 } & DS & Mid May & 0.085 & Late Sep. & 0.094 & Late Aug & 0.11 \\
\hline
\end{tabular}

to determine the timing of $\mathrm{OG}$ and OD of the forest, grassland, and desert steppe. NDVI-derived OG showed variation among the vegetation types while the EVI-derived OG of the vegetation types was identical. An average date of OG estimated from NDVI occurred in the middle of May in the forest and its threshold was 0.361 . Grassland and desert steppe exhibited average onset date in the middle of June with the thresholds of 0.234 and 0.122 , respectively. However, EVI showed that the average dates of OG were in the middle of May for all vegetation types and corresponding thresholds were 0.193 in forest, 0.126 in grassland and 0.085 in the desert steppe. Both NDVI and EVI curves revealed that the average dates of
OD did not show any difference between vegetation types; all occurred in late September. Nevertheless, the thresholds of NDVI and EVI for the average dates of OD differ considerably among the vegetation types, with the values of 0.469 and 0.155 for forest, 0.225 and 0.140 for grassland, and 0.135 and 0.094 for desert steppe. These average date and thresholds were basically used to define phenological events for each vegetation type in each year over the 10 years of the observation period.

\section{Temporal trends in phenological events}

Figure 5 shows descriptive statistics of the both NDVI and EVI-derived phenological 


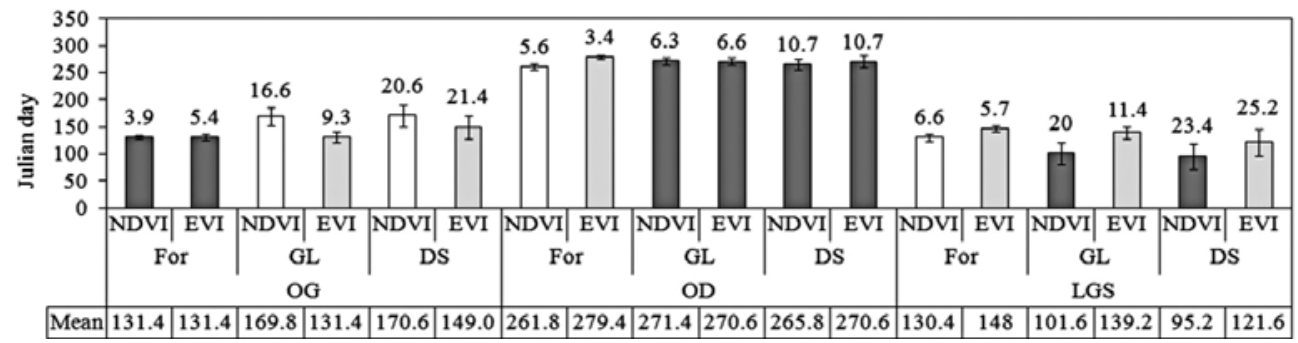

Figure 5 ANOVA based descriptive statistics of OG, OD and LGS in each vegetation types as described by NDVI and EVI. The numbers below the vegetation type indicate Julian day and the error bar with a number above each bar shows the standard deviation of phenological events. The dark grey color represents the same grouping which indicates the similarity of the phenological variables derived from NDVI in comparison with those of derived from EVI. The grey color in LGS shows that LGS of GL and DS derived from the same vegetation index (NDVI) were identical with a probability of 0.05 .

events of vegetation types. There were greater variations in the NDVI-derived OG compared to those derived using EVI. The timing of OG in forest occurred earlier than the other two vegetation types, varying from early May to the middle of May with the mean Julian day of 131.4 \pm 3.9 . In grassland and desert steppe the mean dates of OG were close to each other (Julian day 169.8 \pm 16.6 and 170.6 \pm 20.6 ), having higher variation in desert steppe \pm 20.6 which correspond to middle of May to the middle of July.

In contrast to the NDVI-derived results, the EVI provide relatively stable estimates of the phenological events. OG of the grassland and the desert steppe has been determined at the 131 and 149 Julian day, around 38 and 21 days earlier than those derived from NDVI. Forest and grassland have the same timing of $\mathrm{OG}$

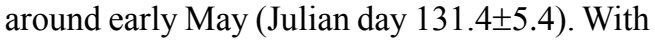
regard to OD, EVI-derived OD of the grassland and the desert steppe were very close to the NDVI-derived OD for the same vegetation types as seen by mean Julian day and standard deviation (Fig 5). But the EVI-derived $\mathrm{OD}$ of the forest occurred on average 15 days later than the NDVI-derived date. In general, there were no differences between NDVI and EVI-derived OG of forest, OD of GL and DS. Both VIs revealed that LGS of each vegeta182 tion type was highly different in timing due to the high variations of OG. As shown in Fig 5, NDVI indicated that LGS lasted for about 4 months (Julian day 130.4 \pm 6.6 ) in forest, and for around 3 months in GL (101.6 \pm 20.0$)$ and in DS (95.2 \pm 23.4$)$. Generally, this suggests that desert steppe was the most variable in timing with a standard deviation (SD) of 24 days. In contrast to the desert steppe, the forest had the most consistent results with a SD of 7 days. This phenomenon is also suggested by EVI, in which forest, grassland, and desert steppe is shown as having experienced LGS for about 5

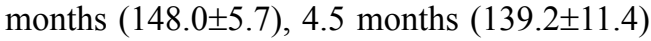
and 4 months (121.6 \pm 25.2$)$, respectively.

Figure 6 depicts some temporal features of the vegetation phenology. Both NDVI and EVI agreed that little annual variations in timing of phenological events were associated with forest. The largest deviation from the 10-year averages OG (Fig 6-1), OD (Fig 6-2) and LGS (Fig 6-3) was less than 15 days. NDVI-derived OG and LGS of grassland and desert steppe fluctuated considerably during the study period. Two most noticeable values can be found at the years, 2003 and 2007 (Figs 6-1a and 6-3a). Variations in OD for all vegetation types are mostly less than 10 days and are in general smaller than OG and LGS (Fig 6-2a). EVI-derived OD of grassland and desert steppe be- 

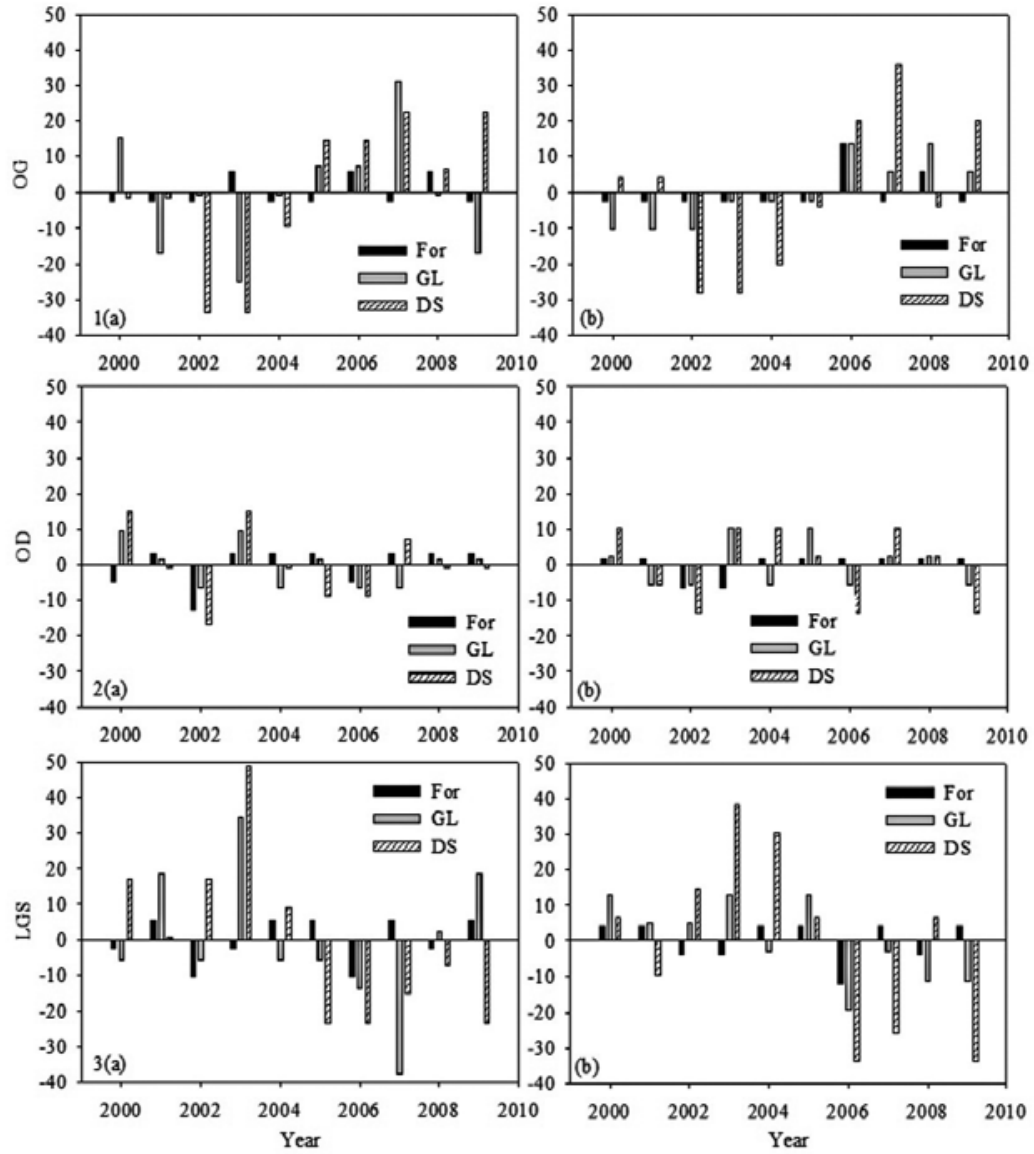

Figure 6 Annual deviations of phenological events: OG (1), OD (2) and LGS (3) deviations from 10-year mean derived from NDVI (a) and EVI (b).

haved similar to each other with an exception in 2004 where the deviation of grassland and desert steppe was negative and positive with a value less than 10 days (Fig 6-2b). In contrast, the EVI-derived OG and LGS of DS changed dramatically in comparison to OD. The most negatively observed values of OG was in 2002 and 2003, while the most positively observed value was in 2007 (Fig 6-1b). In contrast, the most significant LGS of DS appeared positively in 2003 and 2004 and negatively in 2006, 2007, and 2009 (Fig 6-3b).

Table 3 shows the Pearson's correlation coefficients between the deviations of the timing of phenological events (OG, OD, and LGS) and the deviations of the climatic variables (precipitation and temperature). The deviation was calculated based on the long term (10 year) mean of each corresponding variable. As shown in Table 3, the NDVI-derived OG, OD, and LGS of the grassland was positively related to the precipitation whose correlation coefficient was $0.707(\mathrm{P}<0.05), 0.692$ $(\mathrm{P}<0.05)$, and $0.807 \quad(\mathrm{P}<0.01)$ respectively. This indicates that the variation of precipitation regulates the variations of $\mathrm{OG}, \mathrm{OD}$, and LGS. However, this significance was not observed in the forest and the desert steppe. NDVI-derived LGS of DS was positively related to precipitation $(\mathrm{r}=0.793, \mathrm{P}<0.01)$ and none of 
Table 3 Pearson's correlation coefficients between the deviations of phenological events and the deviations of climatic variables (precipitation and temperature).

\begin{tabular}{|c|c|c|c|c|c|c|}
\hline \multirow{2}{*}{ VIs } & \multirow{2}{*}{$\begin{array}{l}\text { Vegetation } \\
\text { types }\end{array}$} & \multirow{2}{*}{$\begin{array}{l}\text { Phenological } \\
\text { events }\end{array}$} & \multirow{2}{*}{$\frac{\text { Precipitation }}{r}$} & \multicolumn{3}{|c|}{ Temperature } \\
\hline & & & & Sig. & $r$ & Sig. \\
\hline \multirow{9}{*}{ NDVI } & \multirow{3}{*}{ For } & OG & 0.004 & 0.991 & $0.773 * *$ & 0.009 \\
\hline & & OD & 0.110 & 0.762 & 0.125 & 0.731 \\
\hline & & LGS & 0.091 & 0.802 & 0.560 & 0.092 \\
\hline & \multirow{3}{*}{ GL } & OG & $0.707 *$ & 0.022 & 0.540 & 0.107 \\
\hline & & OD & $0.692 *$ & 0.027 & -0.284 & 0.426 \\
\hline & & LGS & $0.807 * *$ & 0.005 & -0.540 & 0.107 \\
\hline & \multirow{3}{*}{ DS } & OG & 0.624 & 0.054 & $-0.702 *$ & 0.024 \\
\hline & & OD & 0.552 & 0.098 & 0.097 & 0.790 \\
\hline & & LGS & $0.793 * *$ & 0.006 & -0.575 & 0.082 \\
\hline \multirow{9}{*}{ EVI } & \multirow{3}{*}{ For } & OG & 0.114 & 0.753 & $0.666^{*}$ & 0.036 \\
\hline & & OD & 0.493 & 0.148 & 0.216 & 0.549 \\
\hline & & LGS & 0.185 & 0.610 & $0.764 *$ & 0.010 \\
\hline & \multirow{3}{*}{ GL } & OG & 0.095 & 0.794 & -0.142 & 0.695 \\
\hline & & OD & 0.500 & 0.141 & 0.130 & 0.720 \\
\hline & & LGS & 0.365 & 0.300 & 0.040 & 0.912 \\
\hline & \multirow{3}{*}{ DS } & $\mathrm{OG}$ & 0.370 & 0.293 & $-0.667 *$ & 0.035 \\
\hline & & OD & 0.080 & 0.826 & 0.264 & 0.461 \\
\hline & & LGS & 0.348 & 0.325 & -0.454 & 0.188 \\
\hline
\end{tabular}

Note. Abbreviation: * and ** represent a coefficient is significant at the 0.05 and 0.01 level respectively (2-tailed).

the forest phenological events was significantly related to the precipitation. In contrast, the correlation between EVI-derived OG, OD, and LGS of the grassland and the precipitation was insignificant. However, EVI-derived OG of the forest is positively related to the temperature $(\mathrm{r}=0.666, \mathrm{P}<0.05)$ while that of the desert steppe is negatively related to the temperature $(\mathrm{r}=-0.667, \mathrm{P}<0.05)$. The EVI-derived LGS of the forest and the temperature was also positively related $(\mathrm{r}=0.764, \mathrm{P}<0.01)$.

The agreement between the NDVI- and EVI-derived phenological events of the vegetation types

Based on the results of ANOVA (Fig 5), the NDVI-derived forest OG, grassland OD, and 184 desert steppe OD are not different from the timing of the corresponding event derived by EVI. In contrast, the NDVI-derived forest OD, grassland OG, and desert steppe OG are significantly different from the EVI-derived events at the 0.05 probability level. Due to one of the dates of $\mathrm{OG}$ and $\mathrm{OD}$ in each vegetation type being significantly altered; the LGS of vegetation types was, therefore, different between the NDVI and EVI. The value of LGS among the vegetation types differed significantly at 0.05 probability level for both cases of NDVI and EVI. Based on NDVI, LGS of forest is significantly greater than that of grassland and desert steppe, but the LGS difference between grassland and desert steppe is not significant; also based on EVI, the relative relationship of LGS among the vegetation types is forest $>$ grass- 
land $>$ desert steppe.

In this paper, a relative quantity model is defined as a pattern of the relative quantity of LGS in forest, grassland, and desert steppe. As shown in Table 4, model a is a decreasing linear pattern which indicates a situation where the relative quantity of LGS is forest $>$ grassland $>$ desert steppe, and model $\mathrm{b}$ is an increasing linear pattern, an inverse relative quantity pattern of model a, i.e., forest $<$ grassland $<$ desert steppe. Model c, a v-shape pattern, stands for forest $>$ grassland $<$ desert steppe. Model $\mathrm{d}$ indicates that the relative quantity of LGS of the vegetation types is the forest $=$ grassland $>$ desert steppe, and model e is used for forest $>$ grassland $=$ desert steppe. Examples of Model a are demonstrated by 2001, 2005, 2006, 2008, for the NDVI and 2009, and 2001, 2006, 2007, and 2009 for the EVI. This case is considered as partial agreement because a positive agreement between NDVI and EVI existed at the years 2001, 2006, 2009, while there also existed another negative agreement in the years 2005 (NDVI vs. EVI = model a vs. model d), 2007 (NDVI vs. EVI = model c vs. model a), and 2008 (NDVI vs. EVI = model a vs. model e). The year 2001, 2006, 2009 is classified as model a, 2003 as model b, 2004 as model c simultaneously by NDVI and EVI, this case may be considered as absolute agreement.

\section{Discussion}

The gradient of phenological events derived from both VIs roughly corresponded to the temperature and precipitation gradient of Mongolia; mean annual precipitation decreases as annual temperature increases from a north to south direction. With the spatial pattern of precipitation/temperature in mind, we characterized the seasonal changes of the forest, grassland and desert steppe and examined the consistency of the result of this study in comparison to other studies.

NDVI indicated that the mean date of $\mathrm{OG}$ was generally earliest and stable in the forest, and progressively later and variable in grassland and in desert steppe (Fig 5) whereas EVI showed the mean date of OG in grassland occurs early and at the same date of OG in forest. The earlier OG in forest is closely consistent with the findings demonstrated by Myneni et al. (1998) for high latitudes $\left(>45^{\circ} \mathrm{N}\right)$. Several studies revealed that the timing of $\mathrm{OG}$ in grassland is controlled by precipitation rather than temperature (Zhou et al. 2002, Yu et al. 2003 \& 2004, Dugarsuren \& Lin 2011, Mu et

Table 4 Relative quantity model of LGS for the forest, grassland and desert steppe ecosystems

\begin{tabular}{lll}
\hline Representatives based on NDVI & Relative quantity model* & Representatives based on EVI \\
\hline $2001,2005,2006,2008,2009$ & (b) & (a) \\
$2000,2001,2006,2007,2009$ & 2003 \\
& (c) 2004, 2007 & (d) \\
& (e)
\end{tabular}

Note. Abbreviation: *: The green, blue, and red circles in "relative quantity model" column stand for forest, grassland, and desert steppe respectively; and the level of the circle indicates the relative quantity among the vegetation types. 
al. 2012, Lin \& Dugarsuren 2015). Conversely, in the forest, temperature plays a main role in the timing of OG (Dugarsuren \& Lin 2011, Chu \& Guo 2012). Shinoda et al. (2007) observed the distinctive soil moisture pattern of Mongolia and investigated how the pattern of soil moisture controlled the timing of OG of a specific plant (stippa spp.), dominant in grassland (steppe). This research divided seasonal change of soil moisture into 3 phases: phase-1 spring drying (Apr to late May), phase-2 summer recharging (late May to late July) and phase-3 autumn drying (Aug to Oct) based on the long-term soil moisture data. Soil moisture tends to exhibit slight increase during early April due to snowmelt and then a decrease until the onset of the rainy season (beginning of phase-2) as evapotranspiration exceeds precipitation. During phase-2, soil moisture continues to increase and reach a peak between late July and Aug when precipitation exceeds evapotranspiration. Phase-3 occurs when precipitation is less than evapotranspiration from late Aug to mid-October. After mid-October, soil moisture was assumed to be constant when the daily air temperature was $<0^{\circ} \mathrm{C}$. This pattern of the soil moisture model generally corresponds with the pattern of precipitation in Mongolia (Xue 1996, Nandintsetseg \& Shinoda 2011). So, the seasonal variation of the precipitation cycle suggested that the plant emergency may occur around the transition period from Phase I to Phase II, which was identified as late May to early June, if precipitation recharging lately or anomalously.

In our study, EVI revealed the mean date of OG in grassland was the Julian day of 131 (mid-May) (Fig 5) corresponding to the pattern obtained from the soil moisture model. The responses of vegetation types with different morphology to the pattern of soil moisture are different because of different root systems. Shallow-rooting vegetation types such as grassland and desert steppe lose their surrounding soil moisture easily resulting in unstable photosynthetic activity whereas trees can sustain stable and longer photosynthetic activity than grasses because of deep-root systems which have a capacity to tap deeper soil moisture (Ma et al., 2007). The largest mean of the OD was found in grassland and desert steppe followed by forest, indicating that forest stops growing earlier than grassland and desert steppe due to the high elevation and latitudinal gradient of temperature and precipitation. Although there were small variations in the timing of OD, this is directly connected with descending temperature throughout Mongolia. Temperature decreases dramatically in early October when monthly mean air temperature becomes less than $0^{\circ} \mathrm{C}$, making it impossible for plants to grow in the resulting stressful condition.

The result obtained during the 10 years of observation showed that the latest occurrence of OD could be observed no later than October (in early October). Peaks of NDVI and EVI values, indicative of high photosynthetic and biomass accumulation, were found in late July to late August, which can be explained by being the period with the highest precipitation in Mongolia. Moreover, the occurrence of peak values was consistent with the peak of soil moisture during phase-2 (Nandintsetseg \& Shinoda 2011). Around 85 percent of the precipitation falls in the warm period of the year between April and September, of which 50-60 percent is received in July-August (Natsagdorj et al. 2005). Therefore, precipitation and summer drought in combination with temperature (which will increase evapotranspiration and further reduce soil moisture) will presumably result in a shift of the phenological activities of forest, grassland and desert steppe in Mongolia, with earlier onset of winter-spring growth being offset to some degree by an earlier, and longer lasting, summer drought period. Severe drought frequency in spring and early summer leads to low productivity of vegetation and delayed OG. According to the findings of Bayasgalan \& Dash (2002), drought scale and frequency has increased in Mongolia. 
Drought covering $25 \%$ of the total territory is occurring once in every 2-3 years, and more severe drought that encompasses over $50 \%$ of the total territory happens every 4-5 years. Inter-annual dynamics of NDVI and EVI showed that the shortest growing season in conjunction with late timing of OG, over the 10-year study period occurred in 2005 to 2007 at grassland and desert steppe. Based on the findings of Bayasgalan \& Dash (2002) and Batima (2003) this could be explained by drought frequency within those years.

As shown in Fig 5, both VIs demonstrated similar seasonal events that represented the basic phenological specification of each vegetation type. A notable difference was found between the NDVI and EVI time series, the latter having the tendency to indicate a longer growing season. This result correspond well to EVI's design, which it was proposed had more sensitivity to changes in high biomass areas as compared to the NDVI (Huete et al. 1994). NDVI, however, found greater values than those of EVI (Fig 4), consistent with the findings of Tucker (1979). Plants produce biomass by photosynthesis via the chlorophyll absorption of the energy in blue and red spectral region (Huete et al. 2002). High concentration of leaf chlorophylls leads to lower reflectance of the blue and red radiation (Lin et al. 2015). Integration of blue and red reflectance can, therefore, help to improve the performance of leaf chlorophyll estimation, in particular, to derive effective chlorophyll indicators for accurate chlorophyll estimation (Lin et al. 2015). Based on this advantage of EVI over NDVI it would be expected that EVI should be more appropriate for vegetation phenology extraction. However, with regard to the responses of different vegetation types to the specific pattern of climatic factors and the consistency of NDVI derived timing of phenological events of each vegetation type with the results of previous studies (Yu et al. 2003, 2004; Jigmed 2006, Shinoda et al. 2007, Nandintsetseg et al. 2011), the performance of NDVI and EVI in the determination of the phenological activity should be studied continuously in particular with the aid of monthly and daily-based climate data.

\section{Conclusions}

This study investigated the timing of phenological events, temporal patterns of phenological events, and the differences of NDVI- and EVI-derived phenological events of the major vegetation types: forest, grassland and desert steppe of Mongolia over the 10 year period from 2000-2009. The timing of phenological events showed large variations. The mean date of OG was generally different in each vegetation types; earliest and most stable in forest, and progressively later and variable both in grassland and in desert steppe while the timing of OD showed no significant difference between vegetation types. Vegetation types which experienced high positive and negative variations might be especially vulnerable to global change and are likely to be strongly affected by meteorological changes. However, phenological events extracted from NDVI and EVI are not in complete agreement with each other. NDVI indicated the growing season of the forest, grassland, and desert steppe ecosystems started from early May, middle June, and middle June respectively, and then lasted for around 130.4 $\pm 6.6,101.6 \pm 20.0$, and $95.2 \pm 23.4$ days respectively. In contrast, the EVI-determined growing season of the forest, grassland, and desert steppe started from early May, early May, and middle May and then continued $148 \pm 5.7,139 \pm 11.4$, and 121.6 \pm 25.2 respectively. The phenology of forest is more sensitive to temperature. The phenology of the grassland and the desert steppe however is sensitive to both precipitation and temperature.

The results presented in this study have demonstrated the potential of seasonal dynamics of multi-temporal VIs for use in the discrimination of vegetation phenology. Future 
studies should utilize ground measurement data to explore which vegetation index is the best for representing phenological events and also their relationships with not only climatic variables and the effects of lag time of climatic variables on the timing of phenological events but also with other variables such as soil moisture and carbon content and topography.

\section{References}

Batima P., 2003. Potential impacts of climate change and vulnerability and adaptation assessment for grassland ecosystem and livestock sector in Mongolia. Climate change: Pasture and Livestock. Synthetic Report. Admon Printing-house, Ulaanbaatar, Mongolia, pp. 36-47.

Batima P., Dagvadorj D., 2000. Climate change and its impacts in Mongolia. JEMR Press, Ulaanbaatar, Mongolia.

Batjargal Z., 1996. Nature and environment in Mongolia. Ministry of Nature and the Environment, Ulaanbaatar, Mongolia.

Bayasgalan M., Dash M., 2002. Drought and desertification assessment. Proceedings of strengthening capacity for mitigating drought impact and desertification control, Ulaanbaatar, Mongolia, pp. 29-35.

Chen X. Q., Xu C. X., Tan Z. J., 2001. An analysis of relationships among plant community phenology and seasonal metrics of Normalized Difference Vegetation Index in the northern part of the monsoon region of China. International Journal of Biometeorology 45: 170-177. DOI: $10.1007 / \mathrm{s} 004840100102$

Chesnoiu E., Sofletea N., Curtu A., Toader A., Radu R., Enescu M., 2009. Bud burst and flowering phenology in mixed oak forest from Eastern Romania. Annals of Forest Research 52(1): 199-206

Chu T., Guo X., 2012. Characterizing vegetation response to climatic variations in Hovsgol, Mongolia using remotely sensed tim series data. Earth Scinece Research $1: 2$.

Dugarsuren N., Lin C., 2011. Investigation of vegetation dynamics of Mongolia using time series of NDVI in response to temperature and precipitation. Mongolian Journal of Biological Science 9: 9-17.

Dugarsuren N., Lin C., Tsogt K., 2011. Land cover change detection in Mongolia in last decade using MODIS imagery. Proceeding of ACRS2011. Taipei, Taiwan, pp. 688.

Gao Q., Yu M., 1998. A model of regional dynamics and its application to the study of Northeast China Transect (NECT) responses to global change. Global Biogeochemical Cycles 12: 329-344. DOI: 10.1029/97GB03659

Gomboluudev P., 2008. Vulnerability of rural people to extreme climate events in Mongolia. Workshop of Netherlands Climate Assistance Project (NCAP).

Haggerty B. P., Mazer S. J., 2008. The Phenology Handbook - A guide to phenological monitoring for students, teachers, families, and nature enthusiasts. University of California, Santa Barbara: Santa Barbara, California, USA, 2-20 p.

Huete A. R., Liu H. Q., Batchily K., van Leeuwen W., 1997. A comparison of vegetation indices over a global set of TM images for EOS-MODIS. Remote Sensing of Environment 59: 440-451. DOI: 10.1016/S00344257(96)00112-5

Huete A., Didan K., Miura T., Rodriguez E. P., Gao X., Ferreira L. G., 2002. Overview of the radiometric and biophysical performance of the MODIS vegetation indices. Remote Sensing of Environment 83: 195-213. DOI: $10.1016 / \mathrm{S} 0034-4257(02) 00096-2$

Huete A., Justice C., Liu H., 1994. Development of vegetation and soil indices for MODIS-EOS. Remote Sensing of Environment 49: 224-234. DOI: 10.1016/00344257(94)90018-3

Jeong S. J., Ho C. H., Gim H. J., Brown M. E., 2011. Phenology shifts at start vs. end of growing season in temperate vegetation over the Northern Hemisphere for the period 1982-2008. Global Change Biology 17: 23852399. DOI: $10.1111 /$ j.1365-2486.2011.02397.x

Jigmed G., 2006. The current situation of grassland resources in Mongolia. Bulletin of the Faculty of Agriculture, Niigata University 58: 133-136.

Justice C. O., Vermote E., Townshend J. R. G., Defries R., Roy D. P., Hall D. K., Salomonson V. V., Privette J. L., Riggs G., Strahler A., Lucht W., Myneni R. B., Knyazikhin Y., Running S. W., Nemani R. R., Zhengming Wan., Huete A. R., Van Leeuwen W., Wolfe R. E., Giglio L., Muller J., Lewis P., Barnsley M. J., 1998. The Moderate Resolution Imaging Spectroradiometer (MODIS): land remote sensing for global change research. IEEE Transanctions on Geoscience and Remote Sensing 36: 1228-1249.

Kaduk J., Heiman M., 1996. A Prognostic Phenology Scheme for Global Terrestrial Carbon Cycle Models. Climate Research 6: 1-19. DOI: 10.3354/cr006001

Lee R., Yu F., Price K. P., 2002. Evaluating vegetation phenological patterns in Inner Mongolia using NDVI time-series analysis. International Journal of Remote Sensing 23: 2505-2512. DOI: 10.1080/01431160110106087

Lin C., Popescu S. C., Huang S. C., Chang P. T., Wen H. L., 2015. A Novel Reflectance-based Model for Evaluating Chlorophyll Concentration of Fresh and Water-Stressed Leaves. Biogeosciences 12: 49-66. DOI: 10.5194/bg-12-49-2015

Lin C., Dugarsuren N., 2015. Deriving the Spatiotemporal NPP Pattern in Terrestrial Ecosystems of Mongolia using MODIS Imagery. Photogrammetric Engineering and Remote Sensing 81(7): 587-598. DOI: $10.14358 /$ PERS.81.7.587

Ma S., Baldocchi D. D., Xu L., Hehn T., 2007. Inter-an- 
nual variability in carbon dioxide exchange of an oak/ grass savanna and open grassland in California. Agriculturural of Forest Meteorology 147: 157-171. DOI: 10.1016/j.agrformet.2007.07.008

Menzel A., Sparks T. H., Estrella N., Koch E., Aasa A., Ahas R., Alm-Kubler K., Bissolli P., Braslavska O., Briede A., Chmielewski F. M., Crepinsek Z., Curnel Y., Dahl A., Defila C., Donnelly A., Filella Y., Jatcza K., Mage F., Mestre A., Nordli O., Penuelas J., Pirinen P., Remisova V., Scheifinger H., Striz M., Susnik A., Van Vliet A. J. H., Wielgolaski F. E., Zach S., Zust A., 2006. European phenological response to climate change matches the warming pattern. Global Change Biology 12: 1969-1976. DOI: 10.1111/j.13652486.2006.01193.x

Moulin S., Kergoat L., Viovy N., Dedieu G., 1997. Global-scale assessment of vegetation phenology using NOAA/AVHRR satellite measurements. Journal of Climate 10: 1154-1170. DOI: 10.1175/1520-0442(1997)010<1154:GSAOVP $>2.0$. $\mathrm{CO} ; 2$

Mu S. J., Chen Y. Z., Li J. L., Ju W. M., Odeh I. O. A., Zou X. L., 2012. Grassland dynamics in response to climate change and human activities in Inner Mongolia, China between 1985 and 2009. Rangeland Journal 35: 315329. DOI: $10.1071 /$ RJ12042

Myneni T., Myneni R., Tucker C., Asrar G., Keeling C., 1998. Interannual variations in satellite-sensed vegetation index data from 1981 to 1991. Journal of Geophysical Research 103: 6145-6160. DOI: 10.1029/97JD03603

Nandintsetseg B., Shinoda M., 2011. Seasonal change of soil moisture in Mongolia: its climatology and modelling. International Journal of Climatology 8: 11431152. DOI: $10.1002 /$ joc. 2134

Natsagdorj L., Gomboluudev P., Batima P., 2005. Climate change and its projections. Batima P., Myagmarjav B., (eds), Climate change in Mongolia. Admon Printing house, Ulaanbaatar, Mongolia, pp. 39-84.

Parmesan C., 2006. Ecological and evolutionary responses to recent climate change. Annual Review of Ecology Evolution and Systematics 37: 637-669. DOI: 10.1146/ annurev.ecolsys.37.091305.110100

Piao S., Fang J., Zhou L., Ciais P., Zhu B., 2006. Variations in satellite-derived phenology in China's temperate vegetation. Global Change Biology 12: 672-685. DOI: 10.1111/j.1365-2486.2006.01123.x

Reed B. C., Brown J. F, VanderZee D., Loveland T. R., Merchant J. W., Ohlen D. O., 1994. Measuring phenological variability from satellite imagery. Journal of Vegetation Science 5: 703-714. DOI: 10.2307/3235884

Running S. W., Justice C. O., Salomonson V., Hall D., Barker J., Kaufmann Y. J., Strahler A. H., Huete A. R., Muller J. P., Vanderbilt V., Wan Z. M., Teillet P., Carneggie D., 1994. Terrestrial remote sensing science and algorithms planned for EOS/MODIS. International Journal of Remote Sensing 15: 3587-3620. DOI: $10.1080 / 01431169408954346$
Sacks W. J., Kucharik C. J., 2011. Crop management and phenology trends in the U.S. Corn Belt: Impacts on yields, evapotranspiration and energy balance. Agricultural and Forest Meteorology 151: 882-894. DOI: 10.1016/j.agrformet.2011.02.010

Serbin S. P., Gower S. T., Ahl D. E., 2009. Canopy dynamics and phenology of a boreal black spruce wildfire chronosequence. Agricultural and Forest Meteorology 149: 187-204. DOI: 10.1016/j.agrformet.2008.08.001

Shen M., Tang Y., Chen J., Zhu X., Zheng Y., 2011. Influences of temperature and precipitation before the growing season on spring phenology in grasslands of the central and eastern Qinghai-Tibetan Plateau. Agricultural and Forest Meteorology 151: 1711-1722. DOI: 10.1016/j.agrformet.2011.07.003

Shinoda M., Ito S., Nachinshonhor G. U., Erdenetsetseg D., 2007. Phenology of Mongolian grasslands and moisture conditions. Journal of Meteorolofical Soceity of Japan 85: 359-367. DOI: 10.2151/jmsj.85.359

Soleimani A., Etemad., Calagari M., Namiranian M., Shirvani A., 2014. Influence of climatic factors on friut morphological traits in Populus euphratica Oliv. Annals of Forest Research DOI:10.15287/afr2014.188

Studer S., Stöckli R., Appenzeller C., Vidale P. L., 2007. A comparative study of satellite and ground-based phenology. International Journal of Biometeorology 51: 405-414. DOI: 10.1007/s00484-006-0080-5

Tsegmid Sh., 1969. Physical geography of Mongolia. Press of Mongolian academy of science, Ulaanbaatar, Mongolia.

Tucker C. J., 1979. Red and photographic infrared linear combinations for monitoring vegetation. Remote Sensing of Environment 8: 127-150. DOI: 10.1016/00344257(79)90013-0

van Oort P. A. J., Zhang T., de Vries M. E., Heinemann A. B., Meinke H., 2011. Correlation between temperature and phenology prediction error in rice (Oryza sativa L.). Agricultural and Forest Meteorology 151: 1545-1555. DOI: 10.1016/j.agrformet.2011.06.012

White M. A., Hoffman F., Hargrove W., Nemani R., 2005. A global framework for monitoring phenological responses to climate change. Geophysical Research Letters 32: L0475. DOI: 10.1029/2004GL021961

Xue Y., 1996. The impact of desertification in the Mongolian and the Inner Mongolian grassland on the regional climate. Journal of Climate 9: 2173-2189. DOI: 10.1175/1520-0442(1996)009<2173:TIODIT >2.0. $\mathrm{CO} ; 2$

Yu F., Price K. P., Ellis J., Kastens D., 2004. Satellite observations of the seasonal vegetation growth in Central Asia. Photogrammetric Engineering and Remote Sensing 70: 461-469. DOI: 10.14358/PERS.70.4.461

Yu F., Price K. P., Ellis J., Shi P., 2003. Response of seasonal vegetation development to climatic variations in eastern central Asia. Remote Sensing of Environment 87: 42-54. DOI: 10.1016/S0034-4257(03)00144-5

Zhang X., Friedl M. A., Schaaf C. B., Strahler A. H., Hodges J. C. F., Gao F., Reed B. C., Huete A., 2003. 
Monitoring vegetation phenology using MODIS. Remote Sensing of Environment 84: 471-475. DOI: 10.1016/S0034-4257(02)00135-9

Zhou G., Wang Y., Wang S., 2002. Responses of grassland ecosystems to precipitation and land use along the Northeast China Transect. Journal of Vegetation Science 13: 361-368. DOI: 10.1111/j.1654-1103.2002. tb02060.x

Zhou L., Kaufmann C. J., Slayback R. K., Shabanov N. V., Myneni R., 2001. Variations in northern vegetation activity inferred from satellite data of vegetation index during 1981 to 1999 . Journal of Geophysical Research 106: 20069-20083. DOI: 10.1029/2000JD000115 